Jurnal Konstruksi Hukum | ISSN: XXXX | E-ISSN: XXXX Vol. 1, No. 2, Oktober 2020, Hal. 291-295| Available online at https://www.ejournal.warmadewa.ac.id/index.php/jukonhum

DOI: https://doi.org/10.22225/jkh.1.2.2568.291-295

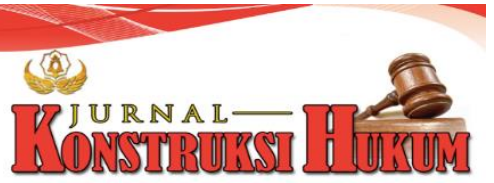

\title{
PENYELESAIAN SENGKETA TANAH KEHUTANAN DI KANTOR PERTANAHAN KABUPATEN BADUNG
}

\author{
I Gede Edy Korneawan, A.A Sagung Laksmi Dewi, Luh Putu Suryani \\ Fakultas Hukum Universitas Warmadewa, Denpasar-Bali, Indonesia
}

\begin{abstract}
Abstrak
Tanah merupakan salah satu bagian terpenting dari permukaan bumi, dimana tanah merupakan sumber kesejahteraan bagi masyarakat. Di dalam UUPA, konsep hak atas tanah di bedakan menjadi dua yaitu, pertama, hak menguasai dari Negara sebagaimana diatur dalam pasal 2 yang berdasarkan penjabaran Pasal 33 UUD Negara Republik Indonesia tahun 1945. Penelitian ini bertujuan untuk mengetahui proses penyelesaian sengketa tanah kehutanan di Kantor Pertanahan Kabupaten Badung. Metode penelitian yang digunakan adalah metode penelitian normatif yaitu mengkaji keputusan kepala kantor wilayah BPN RI dengan Undang-undang yang berlaku. Hasil penelitian analisi menunjukan bahwa berdasarkan Undang-undang Republik Indonesia Nomor 18 tahun 2003 tentang pencegahan dan pemberantasan perusakan hutan disimpulkan penyebap terjadinya sengketa ada 6 . Berdasarkan Perkab BPN No. 3/2011 penyelesaian sengketa pertanahan ada dua melalui litigasi yaitu penyelesaian sengketa melalui jalur pengadilan, dan non litigasi yaitu penyelesaian sengketa melalui mediasi BPN. Melalui penelitian diharapkan kepada pemerintah dapat menentukan tata ruang wilayah sehingga tercipta satu peta tunggal dan tidak tumpang tindih kebijakan antar kementrian Kehutanan dan Dinas Kehutanan.
\end{abstract}

Kata Kunci: Pendaftaran Tanah; Sengketa; Litigasi; Non-Litigasi

\begin{abstract}
Land is one of the most important parts of the earth's surface, where land is a source of welfare for the community. In the UUPA, the concept of land rights is differentiated into two, namely, first, the right to control of the State as regulated in article 2 which is based on the elaboration of Article 33 of the 1945 Constitution of the Republic of Indonesia. This study aims to determine the process of resolving forestry land disputes at the Land Office of Badung regency. The research method used is the normative method, namely examining the decision of the head of the BPN RI regional office with the applicable law. The results of the analysis show that based on the Law of the Republic of Indonesia Number 18 of 2003 concerning the prevention and eradication of forest destruction, it is concluded that the causes of the dispute are 6. Based on the Perkab BPN No. 3/2011 there are two land dispute resolution through litigation, namely dispute resolution through court channels, and non-litigation, namely dispute resolution through BPN mediation. Through research, it is hoped that the government can determine the spatial layout of the area so that a single map is created and there are no overlapping policies between the Ministry of Forestry and the Forestry Service.
\end{abstract}

Keywords: Land Registration; Disputes; Litigation; Non-Litigation

\section{PENDAHULUAN}

Tanah merupakan salah satu bagian terpenting dari permukaan bumi karena tanah merupakan sumber kesejahteraan bagi masyarakat. Secara khusu di Indonesia mempunyai Undang-undang Perlindungan Agraria (selanjutnya disebut sebagai UUPA). Di dalam UUPA, konsep hak atas tanah dibedakan menjadi dua yaitu, pertama, hak menguasai dari Negara sebagaimana diatur dalam pasal 2 yang berdasarkan penjabaran Pasal 33 UUD Negara Republik Indonesia tahun 1945. Negara tidak memiliki tanah, tapi yang memiliki tanah adalah rakyat baik secara sendiri-sendiri, maupun bersama-sama atau dalam bentuk badan hukum. Negara menguasai tanah karena Negara merupakan organisasi tertinggi dan sebagai dasar dari hak-hak yang diberikan kepada masyarakat atau badan hukum (Yasa, 2018).

Pendaftaran tanah memiliki beberapa tujuan, pertama untuk memberikan kepastian hukum dan perlindungan hukum kepada pemegang hak atas suatu bidang tanah, satuan rumah susun,dan hak-hak lain yang terdaftar agar dengan mudah dapat membuktikan dirinya sebagai pemegang hak yang 
bersangkutan. Kedua pendaftaran tanah bertujuan untuk menyediakan informasi kepada pihak-pihak yang berkepentingan termasuk pemerintah agar dengan mudah dapat memperoleh data yang diperlukan dalam mengadakan perbuatan hukum mengenal bidang-bidang tanah dan satuan rumah susun yang sudah terdaftar, serta tujuan terakhir adalah untuk terselenggaranya tertib administrasi pertanahan, seperti yang dijelaskan pada PP Nomor 24 Tahun 1997 pasal 3 huruf a, b, dan c (Yasa, 2018). Menurut Wehrmann (2008:9), konflik tanah dapat diartikan sebagai fakta sosial di mana setidaknya dua pihak terlibat, yang akarnya adalah kepentingan yang berbeda atas hak milik atas tanah: hak untuk menggunakan tanah, mengelola tanah, untuk menghasilkan pendapatan dari tanah, untuk mengeluarkan orang lain dari tanah, untuk mentransfernya dan hak untuk mendapatkan kompensasi untuk itu. Sementara menurut Kementerian PPN (2013:6), kasus pertanahan diklasifikasikan menjadi konflik, sengketa dan perkara. Konflik merupakan permasalahan pertanahan yang memiliki nuansa/aspek sosial dan politik yang luas, sedangkan sengketa adalah permasalahan pertanahan yang tidak memiliki nuansa sosial politik yang begitu luas, umumnya permasalahan antarindividu. Kemudian, perkara merupakan konflik dan sengketa yang sudah masuk ke pengadilan, baik pengadilan negeri, tinggi, maupun PTUN.

Salah satu permasalahan pertanahan yang selalu ada hingga kini adalah antara tiga pihak, yaitu Masyarakat, Badan Pertanahan Nasional (BPN), dan Dinas Kehutanan (TAHURA), seperti kasus yang pernah terjadi tahun 2015, diawali pada tahun 2014 pendaftaran permohonan konversi (Pendaftaran Tanah Pertamakali) dari I Wayan R terhadap tanah SPPT No. 51.03.050.004.004-0xxx.x terletak di Desa Jimbaran, Kecamatan Kuta Selatan, Kabupaten Badung, Provinsi Bali, di lengkapi dengan Informasi Penatagunaan Tanah No. 46/9-51.03.xx/II/2012, surat keterangan tanah bekas milik adat No. 593.2/21/P84, Surat pernyataan tanah bekas milik adat tahun 2014, surat pernyataan penguasaan fisik bidang tanah, surat keterangan pembagian harta warisan tahun 2014, surat pernyataan waris, surat pernyataan silsilah tahun 2014. Terhadap permohonan tersebut ditindaklanjuti dengan proses pengukuran bidang tanah dan pengumuman tanggal 31 Oktober 2014 menyatakan tidak ada pihak yang berkeberatan. Maka dengan tidak adanya pihak-pihak yang berkeberatan, terhadap permohonan tersebut diterbitkanlah sertipikat SHM Nomor 20xxx/Jimbaran. Tetapi pada tanggal 7 Mei 2015 Kepala UPT. TAHURA NGURAH RAI mengajukan surat keberatan kepada Kantor Pertanahan Kabupaten Badung, karena diindikasi penerbitan SHM tersebut melanggar kawasan Hutan, dan akhirnya Kepala Kantor Wilayah Badan Pertanahan Nasional Provinsi Bali menerbitkan Surat Keputusan Kepala Kantor Wilayah BPN Provinsi Bali No. 0207/Pbt/BPN.51/XII/2015, tertanggal 15 Desember 2015, tentang pembatalan sertifikat hak milik nomor 20xxx/Jimbaran, luas $810 \mathrm{~m} 2$, surat ukur, tanggal 15 Oktober 2014, atas nama I Wayan R.

Kasus di atas merupakan salah satu kasus sengketa kehutanan yang sering terjadi di wilayah Kantor Pertanahan Kabupaten Badung, terutama yang berbatasan langsung dengan kawasan hutan dan padat penduduk seperti Desa Benoa, Jimbaran, dan Kedonganan, semunanya terletak di Kecamatan Kuta Selatan Kabupaten Badung. Dalam kasus seperti ini Kantor Pertanahan Kabupaten Badung sering di anggap telah gegabah dalam menerbitkan sertifikat di atas tanah kehutanan.

Sebelumnya telah banyak penelitian mengenai sengketa pertanahan, seperti yang dilakukan oleh Fisher, Kim, Latifah, \& Makarom (2017); Sarsono \& Chalim (2018); dan Wowor (2014) tentang fungsi Badan Pertanahan Nasional terhadap penyelesaian sengketa tanah. Kedua, Rokhmad (2013) menganalisis tentang sengketa tanah kawasan hutan dan resolusinya dalam perspektif FIQH. Dimana peneliti mengambil sampel kasus di wilayah Blora, Jawa Tengah, dimana kasus yang terjadi berupa Konflik tanah akibat Eksploitasi Hutan. Namun, perbedaan penelitian baru ini dengan peneliti di atas adalah menitik beratkan pada analisis faktor-faktor penyebap sengketa tanah kehutanan dilihat dari dua sisi peraturan yaitu peraturan-peraturan tanah dan peraturan-peraturan dari Kehutanan, serta bagaimana prosess penyelesaian sengketa yang dilakukan secara Nonlitigasi oleh Badan Pertanahan Nasional berdasarkan dua jenis peraturan diatas saya juga memasukkan tiga buah komponen menjadi satu yaitu Badan Pertanahan Nasional sebagai instansi yang mempunyai kewenangan dalam pendaftaran tanah, Dinas Kehutanan yang mempunyai hak dan kewenangan terhadap kawasan Hutan Raya, dan masyarakat yang memanfaatkan dan memperoleh pelayanan publik dari kedua instansi tersebut. Berdasarkan uraian permasalahan di atas, maka penelitian baru ini bertujuan untuk mengetahui proses penyelesaian sengketa tanah kehutanan di Kantor Pertanahan Kabupaten Badung 


\section{METODE PENELITIAN}

Penelitian ini merupakan penelitian normatif atau disebut juga penelitian hukum doktrinal yang berfokus pada peraturan yang tertulis (Mahmud, 2009). Beranjak dari keputusan Kepala Kantor Pertanahan Kabupaten Badung yang menerbitkan sertifikat hak milik, selang beberapa waktu adanya surat keberatan dari pihak Tanhura Ngurah Rai yang menyatakan bahwa sertifikat tersebut terbit di kawasan kehutanan.

Adapun sumber hukum yang digunakan sebagai data utama yaitu bahan hukum primer berupa Undang-Undang, bahan hukum sekunder berupa buku-buku, jurnal penelitian dan dokumentasi lain yang memiliki hubungan dengan isu permasalahan pada penelitian saat ini. Data dikumpulkan dengan menggunakan teknik studi kepustakaan yaitu data terlebih dibaca dan dicatat, kemudian data diolah dan diinterpresentasikan sesuai kulaitatif dan diberikan contoh sesuai dengan kenyataan di lapangan.

\section{HASIL DAN PEMBAHASAN}

\section{Penyelesaian Sengketa Secara Non-Litigasi}

Penyelesaian sengketa secara non litigasi adalah penyelesaian sengketa diluar peradilan dimana penyelesaian sengketa ini lebih bersifat kekeluargaan. Cara ini menjadi pilihan utama karena dirasa lebih mudah, cepat dan minim biaya dibanding melalui jalur peradilan (Wowor, 2014). Berikut adalah beberapa cara yang dapat ditempuh dalam penyelesaian sengketa secara non-litigasi:

1. Musyawarah atau Negosiasi

Negosiasi melibatkan dua atau lebih pihak yang berkepentingan atau bersengketa, tujuan dari musyawarah adalah untuk mendapatkan kata sepakat untuk sebuah permasalahan. Hasil dari musyawarah atau negosiasi ini adalah penyelesaian kompromi (Compromise solution) (Wiryawan \& Artadi, 2017).

2. Konsiliasi

Konsiliasi adalah sebuah upaya yang ditempuh untuk mempertemukan keinginan dari para pihak yang berselisih agar para pihak sepakat untuk menyelesaikan konflik atau sengketa. Dalam konsiliasi biasanya terdapat seseorang atau tim yang menengahi atau bersikap netral disebut konsiliator.

3. Mediasi

Mediasi adalah suatu proses penyelesaian sengketa dimana para pihak sepakat untuk memanfaatkan bantuan dari pihak ke tiga yaitu mediator. Mediator bersikap netral dan tidak memiliki wewenang untuk mengambil keputusan yang bersifat mutlak (Rokhmad, 2013).

Dalam Perkaban BPN No. 3 Tahun 2011 pada Pasal 27 dijelaskan berdasarkan rekomendasi penanganan sengketa pertanahan selanjutnya dilakukan:

1. Penelitian atau pengolahan data pengaduan

Penelitian ini meliputi penelitian lapangan untuk mengetahui keabsahan data dari pengadu, meneliti data dari pengadu, mencocokan data fisik dengan data yuridis dan data pendukung lainnya, kajian kronologi sengketa, dan analisis aspek yuridis, fisik serta aspek administrasi. Dalam hal ini, untuk menunjang kelengkapan data petugas dapat mencari atau meminta data dari pihak pengadu.

2. Penelitian Lapangan

Dalam kegiatan penelitian lapangan petugas mengumpulkan data data berupa meneliti kesesuaian data dengan sumbernya, mencari keterangan dari saksi-saksi yang terkait kasus, meninjau fisik obyek tanah yang diperselisihkan, meneliti batas tanah, peta bidang, gambar situasi atau surat ukur, dan kegiatan-kegiatan lain yang diperlukan.

3. Menyelenggarakan Gelar Kasus

Gelar kasus yang diadakan oleh badan pertanahan nasional dapat dilakukan dengan beberapa cara yaitu persuasif, fasilitasi, dan mediasi para pihak dalam rangka penanganan sengketa.

4. Penyusunan risalah pengolahan data

Risalah pengolahan data merupakan rangkuman hasil kegiatan penanganan kasus pertanahan.

5. Penyiapan Berita Acara atau Surat Keputusanatau dan atau monitoring dan evaluasi terhadap hasil penanganan sengketa. 
Perbuatan hukum terhadap sertipikat tanah yang cacad administrasi dilakukan dengan Menerbitkan surat keputusan pembatalan atau pencatatan pemeliharaan data pendaftaran tanah. Langkah yang diambil oleh Kantor Pertanahan Kabupaten Badung dalam menyelesaian kasus sengketa tanah secara Non Litigasi yang melibatkan I Wayan R dengan pihak kehutanan sesuai dengan Perkaban BPN No. 3 Tahun 2011 Pasal 27 s/d Pasal 43 serta pembatalan sertifikat Pasal 62.

\section{Penyelesaian Sengketa Secara Litigasi}

Penyelesaian sengketa secara litigasi adalah penyelesaian melalui jalur peradilan. Dalam hal perkara yang melibatkan BPN RI merupakan perkara dalam Tata Usaha Negara, biasanya disini kedudukan dari BPN RI adalah sebagai tergugat. Yang digugat adalah keputusan dari kepala kantor pertanahan kabupaten atau kota atas penerbitan sertipikat hak atas tanah. Dalam Perkaban BPN No. 3 Tahun 2011 disebutkan Penanganan Perkara Pertanahan meliputi perkara perdata dan Tata Usaha Negara yang melibatkan BPN RI. Penanganan perkara meliputi kegiatan penanganan atas tindak lanjut atau pelaksanaan dari putusan lembaga peradilan yang sudah mempunyai kekuatan hukum tetap.

Terhadap putusan pengadilan dalam perkara pertanahan dimana posisi BPN RI kalah, BPN RI dalam hal ini Kantor Pertanahan Kabupaten atau Kota dapat menempuh Upaya Hukum. Upaya hukum yang dapat dilakukan yaitu Banding, Kasasi, Peninjauan Kembali dan Perlawanan terhadap putusan Pengadilan. Upaya hukum dapat dihentikan jika BPN RI meyakini memang tidak diperlukan upaya hukum kecuali terhadap barang milik Negara atau milik daerah. Dalam kondisi perkara perdata yang menyangkut kepentingan BPN RI tetapi BPN RI tidak duduk sebagai tergugat, pihak yang berkepentingan dapat meminta keterangan ahli atau saksi ahli dari BPN RI dengan cara membuat permohonan batuan aparatur BPN RI yang ditujukan kepada Kepala Kantor Pertanahan Kabupaten, Kota, atau wilayah atau langsung ditujukan kepada Kepala Badan Pertanahan Nasional Republik Indonesia.

\section{SIMPULAN DAN SARAN Simpulan}

Penyebap terjadinya sengketa tanah dengan kehutanan karena tidak terpenuhi azas kontradiktur delimitasi, Kurangnya penetapan kawasan hutan, Bentuk penguasaan fisik dari kehutanan yang tidak jelas, Kurangnya tindakan pencegahan dari dinas terkait khususnya kehutanan, Kurangnya perawatan tanda batas kehutanan, Kurangnya Koordinasi Antar Instansi Terkait. Keadaan ini melanggar pasal 17, 18, 19 PP No. 24 Tahun 1997, dan pasal 6, 5, 8 UU RI No. 18 Tahun 2013. Kemudian, Proses penyelesaian sengketa pertanahan yaitu penyelesaian dilakukan dengan cara nonlitigasi atau diluar peradilan, Melakukan Penelitian ulang terhadap obyek sengketa, Rekonstruksi ulang patok kehutanan, Telah melaksanakan pengkajian kasus, Gelar Perkara atau Gelar Kasus, Penyusunan Risalah Pengolahan Data, Ditemukan cacat administrasi, Pembatalan sertifikat hak milik atas nama I WAYAN R. Berdasarkan Perkab BPN No. 3 Tahun 2011 pasal 61, 62, dan 63.

\section{Saran}

Melalui penelitian ini diharapkan kepada instansi terkait BPN RI, Kementrian Kehutanan atau Dinas Kehutanan, Dispenda, dan Dinas Tata Ruang dapat menyamakan persepsi atau peta kawasan dalam menentukan tata ruang wilayah sehingga tercipta satu peta tunggal agar tidak ada lagi tumpang tindih kebijakan yang merupakan salah satu penyebap masalah ini dan Kementrian Kehutanan melalui Dinas kehutanan dapat selalu berkoordinasi dengan baik.

\section{DAFTAR PUSTAKA}

Fisher, L. A., Kim, Y., Latifah, S., \& Makarom, M. (2017). Managing Forest Conflicts: Perspectives of Indonesia's Forest Management Unit Directors, 1(April), 8-26.

Kementerian PPN, B. (2013). Kebijakan Pengelolaan pertanahan Nasional. Jakarta.

Mahmud, M. P. (2009). Penelitian Hukum. Jakarta: Kencana Predia Media Grup.

Rokhmad, A. (2013). Sengketa Tanah Kawasan Hutan dan Resolusinya dalam Perspektif Fiqh. Walisongo, 21(1), $141-170$.

Sarsono, \& Chalim, M. A. (2018). Land Dispute Settlement Through Mediation In The Regional Land Office In Boyolali Regency. Jurnal Akta, 5(2), 369-376.

Wehrmann, B. (2008). Land Conflicts: A Practical Guide to Dealing with Land Disputes. Eschborn: Deutsche 
Gesellschaft für.

Wiryawan, I. W., \& Artadi, I. K. (2017). Penyelesaian Sengketa di Luar Pengadilan: Keterampilan Nonlitigasi Aparat Hukum. Denpasar: Udayana Press.

Wowor, F. (2014). Fungsi Badan Pertanahan Nasional terhadap Penyelesaian Sengketa Tanah. Lex Privatum, 2(2), 95-104.

Yasa, I. G. K. S. (2018). Kedudukan Hukum Pemegang Hak Milik Atas Tanah yang Diperoleh Berdasarkan Putusan Pengadilan yang Telah Mempunyai Kekuatan Hukum Tetap. Universitas Udayana.

Peraturan Kepala Badan Pertanahan Nasional Republik Indonesia Nomor 3 tahun 2011 tentang pengelolaan, pengkajian, dan penanganan kasus pertanahan.

Peraturan Presiden Republik Indonesia Nomor 88 tahun 2017 Tentang Penyelesaian Penguasaan Tanah Dalam Kawasan Hutan. Lembar Negara Republik Indonesia Nomor 196 Tahun 2017.

Undang-undang Nomor 5 tahun 1960 tentang peraturan dasar pokok-pokok agrarian. Lembaran Negara Republik Indonesia Tahun 1960 Nomor 104. 